\title{
STRES KERJA DENGAN PERSEPSI PERILAKU CARING PADA PERAWAT
}

\author{
Nathania Hangewa ${ }^{1}$, Jeavery S. Bawotong 2 , Mario E. Katuuk ${ }^{3}$
}

1. Mahasiswa, Program Studi Ilmu Keperawatan, Fakultas Kedokteran, Universitas Sam Ratulangi, Manado

2. RSUP Prof. Dr. R. D. Kandou, Manado

3. Program Studi Ilmu Keperawatan, Fakultas Kedokteran, Universitas Sam Ratulangi, Manado

Email: nathaniahangewa02@gmail.com

\begin{abstract}
Abstrack
Background The perception of caring behavior is an important thing that must be considered by nurses in providing nursing care. Excessive work stress can affect the quality of health services. The purpose of this study was to determine the relationship between nurses work stress and perception of caring behavior. Method: This study used correlation analytic research design with cross sectional approach. Sample in this study were 34 respondents. Data collection using questionnaire sheets that have been used previously by Nopa (2016) and Rika (2012) whose validity has been tested. The Results using the spearman correlation test, the results obtained $r-0,004$ and p 0,983;0,05. Conclusion, work stress of nurses is not significantly related to the perception of caring behavior in the emergency room and ICU at GMIM General Hospital Pancaran Kasih Manado. Suggestions, for hospitals to be able to improve the quality of nursing services related to the perception of caring behavior in patients.
\end{abstract}

Keywords: work stress, perception of caring behavior

\begin{abstract}
Abstrak
Latar Belakang Persepsi perilaku caring merupakan hal penting yang harus diperhatikan oleh perawat dalam memberikan asuhan keperawatan. Stres kerja yang berlebihan dapat mempengaruhi mutu pelayanan kesehatan yang diberikan. Tujuan penelitianuntuk mengetahui hubungan stres kerja perawat dengan persepsiperilaku caring. Metode penelitian ini menggunakan desain penelitian analitik korelasi dengan pendekatan cross sectional. Sampel dalam penelitian ini sebanyak 34 responden. Pengumpulan data menggunakan lembar kuesioner yang pernah digunakan sebelumnya oleh Nopa (2016) dan Rika (2012) yang telah diuji validitasnya. Hasil penelitian dengan menggunakan uji korelasi spearman, hasil diperoleh nilai $\mathrm{r}-0,004$ dan nilai $\mathrm{p} 0,983 ; \alpha 0,05$. Kesimpulan, stres kerja perawat tidak berhubungan secara bermakna dengan persepsi perilaku caring di IGD dan ICU RSU GMIM Pancaran Kasih Manado. Saran,bagi rumah sakit agar dapat meningkatkan mutu pelayanan keperawatan yang berkaitan dengan berpersepsi perilaku caring pada pasien.
\end{abstract}

Kata Kunci : stres kerja, persepsi perilaku caring. 


\section{PENDAHULUAN}

Stres merupakan kondisi internal atau lingkungan yang membebankan tuntutan penyesuaian terhadap individu. Stres yang berlebihan membuat kinerja seseorang menurun, cenderung tidak produktif, kesehatan menjadi tidak stabil atau mudah sakit dan mengakibatkan depresi. World Health Organization (WHO) dalam model kesehatan dibuat sampai tahun 2020 merumuskan atau memperkirakan penyakit pembunuh kedua setelah penyakit jantung yaitu depresi, artinya dalam 10 besar penyakit yang menyebabkan kematian salah satunya yaitu stres atau depresi (Mochtar dkk, 2013).Dari hasil penelitian yang dilakukan oleh Persatuan Perawatan Nasional Indonesia (2006) terdapat 50,9\% perawat di empat provinsi di Indonesia mengalami stres kerja, dengan keluhan yaitu lelah, sering pusing, beban kerja yang tinggi dan menyita waktu, tidak ada istirahat, gaji rendah dan insentif yang tidak sesuai (Rachmawati, 2009).

Persepsi perilaku caring adalah manifestasi dari perhatian kepada orang lain, berpusat pada orang, menghormati harga diri dan kemanusiaan, komitmen untuk mencegah terjadinya status yang memburuk, memberi perhatian dan konsen, dan menghormati orang lain (Watson, 2012). Seorang perawat harus mampu memahami setiap respon yang berbeda dari pasien terhadap penderitaan yang dialaminya dan memberikan pelayanan kesehatan yang tepat dalam setiap respon yang berbeda baik yang sedang maupun akan terjadi. Selain itu, perilaku persepsi caring hanya dapat ditunjukkan dalam hubungan interpersonal yaitu hubungan yang terjadi antara perawat dengan pasien, dimana perawat menunjukkan perilaku persepsi caring melalui perhatian, intervensi untuk mempertahankan kesehatan pasien dan energi positif yang diberikan pada pasien. Perilaku persepsi caringmeliputi komitmen untuk memberikan pelayanan keperawatan yang didasarkan pada ilmu pengetahuan. Dalam praktiknya, perawat ditantang untuk tidak ragu dalam menggunakan pengetahuan yang dimilikinya dalam praktik keperawatan (Watson, 2012).

Pengambilan data awal oleh peneliti pada tanggal dua dan tiga April 2019 di ruangan IGD dan ICU RSU GMIM Pancaran Kasih Manado, melalui wawancara dengan kepala ruangan ICU didapatkan bahwa perawat pelaksana ICU berjumlah sepuluh orang dengan rata-rata pasien per bulan sebanyak 16 orang. Perawat ICU mengeluh sering kelelahan dan mengalami stres dalam merawat pasien tidak sadar yang menuntut konsentrasi dan kemampuan berpikir kritis dalam memonitoring kondisi pasien yang dapat mengalami perubahan secara mendadak.

Hasil observasi di ICU terlihat bahwa kegiatan-kegiatan yang dilakukan perawat ialah mengangkat pasien, mengatur posisi pasien, melakukan pemberian makanan, pemberian obat, mengobservasi kondisi pasien tiap jam,dan lain-lain serta ketika pasien datangperawat tidak mencuci tangan sebelum menangani pasien baru. Hasil wawancara dengan kepala ruangan IGD diketahui bahwajumlah perawat pelaksana sebanyak 25 orang dan jumlah kunjungan pasien per hari 50-60an pasien dengan jenis penyakit dan tingkat kegawatan yang berbeda-beda. Perawat mengeluh banyak hal yang harus dikerjakan secara cepat dan tepat sehingga sering mengalami kelelahan dan stres. Hasil observasi di IGD didapatkan bahwa kegiatan-kegiatan yang dilakukan oleh perawat yaitu membersihkan ruangan, memasang infus, mengambil spesimen darah, melakukan observasi TTV, melakukan RJP (Resusitasi Jantung Paru), menulis dokumentasi tiap tindakan, menghadapi keluarga pasien yang panik, mengambil berkas-berkas dokumentasi, membersihkan ruangan dan lain-lain serta masih ada dua bed yang tidak 
menggunakan side rail, sebelum melakukan tindakan kepada pasien tidak mencuci tangan dan tidak menggunakan sarung tangan saat pengambilan spesimen darah. Hal itu menunjukkan bahwa kondisi emosional perawat berpengaruh terhadap persepsi pasien, mempengaruhi perilaku persepsicaring perawat. Reaksi emosional yang muncul pada diri perawat dapat berupa stres kerja. Berdasarkan fenomena yang terjadi, perawat memiliki stresor yang tinggi karena perawat setiap hari akan berhadapan dengan aspek lingkungan fisik, psikososial dan sosial yang tinggi dari pekerjaan. Sehingga kemungkinan besar akan terjadi stress pada perawat karena beban kerja yang berlebih.

Berdasarkan dari latar belakang diatas, maka peneliti tertarik untuk meneliti "Hubungan Stres Kerja dengan Persepsi Perilaku Caring Pada Perawat di IGD dan ICU RSU GMIM Pancaran Kasih Manado".

\section{METODE PENELITIAN}

Jenis penelitian ini analitik korelasi dengan pendekatan cross sectional, metode penelitian ini untuk mengetahui hubungan antara dua variabel yaitu variabel independen (stres kerja) dan variabel dependen (persepsi perilaku caring). Penelitian ini dilaksanakan di RSU GMIM Pancaran Kasih Manado pada tanggal 25 September 2019. Populasi penelitian ini adalah jumlah perawat di IGD dan ICU sebanyak 34 orang. Pengambilan sampel menggunakan rumus slovin maka didapatkan jumlah sample 34 untuk perawat IGD dan ICU. Instrumen penelitian yang digunakan untuk mengukur variabel stres kerja dengan persepsi perilaku caring perawat menggunakan kuesioner yang pernah digunakan sebelumnya oleh Nopa (2016) dan Rika (2012) yang telah diuji validitasnya, kuesioner yang digunakan dalam penelitian ini terdiri dari 24 pernyataan untuk stres kerja dan 36 pernyataan untuk persepsi perilaku caringperawat dengan pemberian skor : 1 "Tidak Pernah", 2 "Kadang-kadang", 3 "Sering" dan 4 "Selalu". Setelah lembar kuesioner diisi oleh responden, peneliti mengumpulkan kembali lembar kuesioner.

Pengolahan data yang diperoleh dari hasil penelitian ini menggunakan analisis komputer dengan beberapa tahap yaitu editing, coding, processing dan cleaning (Notoatmodjo, 2010). Analisis bivariat dalam penelitian ini yaitu untuk mengetahui hubungan stres kerja dengan persepsi perilaku caring pada perawat. Peneliti menggunakan uji Spearman Korelasidengan tingkat kemaknaan 95\% $(\alpha=0,05)$. 
HASIL DAN PEMBAHASAN

\section{Karakteristik Responden}

Tabel 1. Distribusi Responden Menurut Jenis Kelamin, Usia, Pendidikan Terakhir dan Lama Bekerja $(\mathrm{N}=34)$

\begin{tabular}{ccc}
\hline Karakteristik Responden & F & \% \\
\hline Jenis Kelamin : & 6 & 17,6 \\
Laki-laki & 28 & 82,4 \\
Perempuan & 34 & 100 \\
Total & & \\
Usia : & 28 & 82,4 \\
21-30 tahun & 3 & 8,8 \\
$31-40$ tahun & 3 & 8,8 \\
$>40$ tahun & 34 & 100 \\
Total &
\end{tabular}

\begin{tabular}{ccc}
\hline Pendidikan Terakhir : & & \\
D III & 23 & 67,6 \\
S1 & 3 & 8,8 \\
Ners & 8 & 23,5 \\
Total & 34 & 100 \\
\hline Lama Bekerja : & 23 & \\
$<5$ tahun & 7 & 67,6 \\
$5-10$ tahun & 4 & 20,6 \\
$>5$ tahun & 34 & 11,8 \\
Total & & 100 \\
\hline
\end{tabular}

Sumber : Data Primer 2020

\section{Jenis Kelamin}

Distribusi responden dilihat dari karakteristik berdasarkan jenis kelamin, hasil menunjukan bahwa perawat di IGD dan ICU paling banyak jenis kelamin perempuan dengan jumlah 28 perawat. Hal ini sejalan dengan penelitian sebelumnya yang dilakukan oleh Nopa (2016) dan Rika (2012) tentang hubungan tingkat stres kerja dengan perilaku caring didapatkan bahwa kebanyakan responden berjenis kelamin perempuan dengan presentase
85,5\%. Secara psikologi, perempuan memiliki sifat atau naluri keibuan yang dibutuhkan dalam melayani, sehingga diharapkan sifat perawat perempuan lebih sabar dan perhatian dalam memberikan pelayanan.

\section{Usia}

Distribusi responden dilihat dari karakteristik berdasarkan usia, hasil menunjukan bahwa perawat di IGD dan ICU paling banyak usia 21-30 tahun. 
Menurut Kumbadewi (2016), usia produktif seorang pekerja berada dalam rentang 15 sampai 65 tahun sehingga dapat terlihat responden dalam penelitian ini tergolong usia produktif. Usia seseorang mempengaruhi tingkat produktivitasnya, semakin meningkat usia pekerjaan maka semakin tinggi juga tingkat produktivitasnya dan jika usia pekerja memasuki lanjut usia maka produktivitasnya menurun karena dipengaruhi oleh beberapa faktor seperti fisik dan status kesehatannya.

\section{Pendidikan Terakhir}

Distribusi responden dilihat dari karakteristik berdasarkan pendidikan terakhir, hasil menunjukan bahwa perawat di IGD dan ICU paling banyak pendidikan terakhir D III dengan jumlah 23 perawat. Menurut Renoningsih (2016), kemampuan seorang perawat dipengaruhi oleh tingkat pendidikannya. Pendidikan yang tinggi dapat meningkatkan kematangan intelektual seseorang sehingga pengetahuan yang dimiliki dapat dikembangkan dan diterapkan dalam pelayanan kesehatan yang diberikan kepada pasien.

\section{Lama Bekerja}

Distribusi responden dilihat dari karakteristik berdasarkan lama bekerja, hasil menunjukkan bahwa perawat di IGD dan ICU RSU GMIM Pancaran Kasih Manado paling banyak lama bekerja dengan jumlah 23 perawat, lama bekerja < 5 tahun. Hasil penelitian Putri (2018) tentang hubungan antara tingkat stres kerja dengan perilaku caring perawat didapatkan bahwa kebanyakan responden memiliki lama bekerja 1-5 tahun sebanyak 28 responden (72\%). Menurut Manorek (2018), lama bekerja bisa mempengaruhi kinerja seseorang. Semakin lama seseorang bekerja maka semakin tinggi pula tingkat kedewasaannya dalam mengelola setiap masalah yang terjadi ditempat kerja.

\section{Analisa Univairat}

Tabel 2. Data Numerik

\begin{tabular}{cccc}
\hline Variabel & Mean & Median & Standar Deviasi \\
\hline Stres Kerja & 59,32 & 64,50 & 12,758 \\
Persepsi Perilaku Caring & 90,32 & 88,50 & 12,932 \\
\hline
\end{tabular}

Sumber : Data Primer 2020

Tabel 3. Distribusi Responden Berdasarkan Stres Kerja dan Persepsi Perilaku Caring (N=34)

\begin{tabular}{ccc}
\hline Variabel & f & \% \\
\hline Stres Kerja : & 4 & 11,8 \\
Ringan & 27 & 79,4 \\
Sedang & 3 & 8,8 \\
Berat & 34 & 100 \\
Total & & \\
Persepsi Perilaku Caring : & 2 & 5,9 \\
Baik & 30 & 88,2 \\
Cukup & 2 & 5,9 \\
Kurang & 34 & 100 \\
Total & &
\end{tabular}




\section{Stres Kerja}

Hasil penelitian ini menunjukkan bahwa nilai rata-rata stres kerja responden adalah mean 59,32 dengan std.deviasi 12,758. Stres kerja merupakan masalah yang muncul ketika individu berinteraksi dengan lingkungan kerjanya. Tinggi rendahnya stres kerja yang dialami oleh individu sangat tergantung bagaimana individu melakukan manajemen stres (Albin \& Fowler, 2012; Berry, 2007). Berdasarkan penelitian Purwandari (2016), perawat pelaksana di RSUD Sragen mempunyai tingkat stres yang rendah $77,8 \% ; 20 \%$ perawat mempunyai stres sedang dan 2,2\% perawat mempunyai stres yang tinggi. Data tersebut berdasarkan penggabungan stres secara keseluruhan baik karena faktor luar organisasi, faktor individu maupun faktor organisasi. Menurut Muchlas (2008) kondisi stres yang dibiarkan akan mempengaruhi kinerja perawat, bahkan dapat mengancam kemampuannya untuk mengatasi lingkungan. Berdasarkan hasil penelitian stres kerja perawat yang bekerja di ruang IGD dan ICU RSU GMIM Pancaran Kasih Manado terdapat lebih banyak mengalami stres kerja sedang seperti perawat yang mengalami sakit kepala ketika bekerja, kelelahan, jenuh, mudah tersinggung dan marah, perubahan pola makan, kesulitan untuk tidur karena memikirkan masalah pekerjaan, dan sering menunda pekerjaan.

\section{Persepsi Perilaku Caring}

Hasil penelitian ini menunjukkan bahwa nilai rata-rata persepsi perilaku caring responden adalah mean 90,32 dengan std.deviasi 12,932. Hal ini didukung oleh penelitian Green (2004) yang menemukan bahwa perilaku caring berdasarkan gender dan area praktik tidak terdapat perbedaan secara signifikan. Penelitian ini menunjukkan bahwa sebagian besar perawat belum menunjukkan persepsi perilaku caring yang sesuai dengan kesepuluh faktor caratif yang merupakan faktor-faktor pembentuk persepsi perilaku caring sehingga kebutuhan biofisik, psikososial, spiritual dan interpersonal pada pasien dapat terpenuhi. Berdasarkan hasil penelitian persepsi perilaku caring pada perawat yang bekerja di ruang IGD dan ICU RSU GMIM Pancaran Kasih Manado terdapat lebih banyak mengalami persepsi perilaku caring seperti yang muncul perawat tidak menerima ekspresi perasaan positif dan negatif pasien atau keluarga, mengidentifikasi masalah yang dihadapi pasien, mendiskusikan masalah yang dikhawatirkan pasien dan kadang-kadang untuk memberikan solusi akan keluhan maupun perasaan yang diutarakan oleh pasien.

\section{Analisa Bivariat}

Tabel 4. Hubungan Stres Kerja dengan Persepsi Perilaku Caring Pada Perawat (N=34).

\begin{tabular}{lccc}
\hline & \multicolumn{3}{c}{ Correlations } \\
\cline { 2 - 4 } & Correlation Coefficient & Sig. (2-tailed) & $\mathrm{N}$ \\
\hline Stres Kerja & $-0,004$ & 0,983 & 34 \\
Persepsi Perilaku Caring & $-0,004$ & 0,983 & 34 \\
\hline
\end{tabular}

Sumber: Data Primer 2020 
Analisa hubungan stres kerja dengan persepsi perilaku caring pada perawat di IGD dan ICU RSU GMIM Pancaran Kasih Manado dengan hasil uji menggunakan uji Korelasi Spearman yang sudah dilakukan Correlation Coefficient dengan $\mathrm{p}$ value. Hasil diperoleh nilai $\mathrm{r}=-$ 0,004 dan nilai $\mathrm{p}=0,983$. $\mathrm{P}$ value lebih besar dari nilai $\alpha=0,05$, sehingga dapat disimpulkan tidak ada hubungan yang signifikan antara stres kerja dengan persepsi perilaku caring pada perawat di IGD dan ICU. Pada penelitian ini, terdapat korelasi stres kerja dengan persepsi perilaku caring pada perawat adalah berat, sebesar $-0,004$ dengan nilai $\mathrm{p}$ value 0,983 , yang menunjukkan koefisien korelasi sangat rendah dan bernilai negatif artinya semakin berat stres kerja perawat maka semakin kurang baik persepsi perilaku caring perawat yang dilakukan. Berdasarkan hal tersebut peneliti berasumsi bahwa salah satu hal yang menyebabkan tidak ada hubungan antara stres kerja dengan persepsi perilaku caring ini yang mempengaruhi adalah faktor usia, perawat dengan usia rentang 21 sampai 30 tahun sebanyak 28 perawat karena usia muda yang memiliki sedikit pengalaman praktik dalam merawat pasien kritis mempunyai tingkat stres kerja sedang sehingga perilaku persepsi caring yang perawat terapkan masih tergolong cukup jika dibandingkan dengan perawat yang sudah mempunyai banyak pengalaman.

Menurut Chan Kwok-Bun (2007) bahwa usia muda juga berhubungan dengan tingkat pengetahuan dan kesiapan perawat dalam menangani pasien. . Hal ini menunjukkan bahwa, walaupun perawat memiliki stres kerja sedang tetapi dengan usia yang muda dapat meningkatnya pengetahuan dalam merawat pasien atau dalam pemberian asuhan keperawatan sehingga perilaku persepsi caring yang perawat terapkan tergolong cukup. Kurangnya sikap perawat yang sabar, patuh dan bertanggung jawab akan menunjukkan kinerja yang kurang baik dari seorang perawat sehingga baik dalam keadaan lelah atau tidak, perawat tetap menunjukkan persepsi perilaku caring yang kurang baik. Tidak ada hubungan antara stres kerja dengan caring perawat yaitu menurut Petry \& Potter (2004) menyatakan bahwa perawat yang tidak mampu menghilangkan stres akan berdampak pada menurunnya penampilan kerja dan memburuknya pelayanan terhadap pasien. Sikap perawat yang baik akan terwujud pada tanggung jawab atas seluruh pekerjaannya dengan segala resiko yang akan dihadapi.

Berdasarkan fenomena yang terjadi, perawat yang memiliki stres kerja yang berat maka persepsi perilaku caring yang dilakukan perawat semakin kurang baik. Banyak faktor yang mempengaruhi seorang perawat dalam melakukan tindakan persepsi perilaku caring dalam pemberian asuhan keperawatan. Stres kerja yang berat dapat mempengaruhi persepsi perilaku caring yang dilakukan oleh perawat untuk mengambil keputusan atau bersikap dalam memberikan asuhan keperawatan. Sehingga persepsi perilaku caring yang dilakukan oleh perawat akan menimbulkan kurangnya waktu untuk mendengarkan keluhan pasien, kurangnya perhatian kepada pasien, kurangnya mengahargai perasaan pasien, kurangnya pemenuhan kebutuhan dasar pasien dan kurangnya memfasilitasi pasien untuk bersosialisasi dengan lingkungan. Potter \& Perry (2010) menyatakan bahwa perilaku caring membantu perawat mengenali intervensi yang baik, dan kemudian menjadi perhatian dan petunjuk untuk memberikan perilaku caring nantinya.

Dari hasil penelitian pada ruang IGD dan ICU RSU GMIM Pancaran Kasih Manado bahwa adanya stres kerja yang berat bagi perawat. Beberapa pasien mengeluhkan seringnya perawat menunjukkan bahwa kurangnya keramahan, kesabaran, peduli dan perhatian. Kepekaan, kecepatan dan ketepatan menanggapi permasalahan pasien juga masih kurang. Adapun didapatkan bahwa perawat mengeluhkan 
adanya stres kerja yang berlebihan di ruang IGD dan ICU sehingga tidak dapat melakukan persepsi perilaku caring dengan baik. Hal itu menunjukkan bahwa kondisi emosional perawat berpengaruh terhadap persepsi pasien dan mempengaruhi persepsi perilaku caring pada perawat. Reaksi emosional yang muncul pada perawat dapat berupa stres kerja. Oleh karena itu stres kerja perawat akan mempengaruhi kondisi persepsi perilaku caring pada pasien seperti kadang-kadang merasakan apa yang dirasakan pasien, berbicara yang sopan, memberikan semangat kepada pasien agar dapat sembuh, memberikan waktu dan mendengarkan keluhan pasien, memfasilitasi pasien untuk bersosialisasi dengan lingkungan dan membantu pasien dalam pemenuhan kebutuhan sehari-hari misalnya makan, minum, personal hygine pada pasien. Sehingga dapat disimpulkan bahwa tidak ada hubungan stres kerja dengan persepsi perilaku caring pada perawat di IGD dan ICU RSU GMIM Pancaran Kasih Manado.

\section{SIMPULAN}

Stres kerja perawat tidak berhubungan secara bermakna dengan persepsi perilaku caring di IGD dan ICU RSU GMIM Pancaran Kasih Manado.

Instuisi pendidikan diharapkan dapat menggunakan hasil penelitian ini sebagai bahan referensi mengenai Stres Kerja dengan Persepsi Perilaku Caring Pada Perawat di IGD dan ICU.

$$
\text { Bagi peneliti selanjutnya }
$$
diharapkan dapat mengembangkan atau meneliti masalah-masalah lain yang berkaitan dengan peningkatan mutu pelayanan keperawatan persepsi perilaku caring pada pasien.

\section{DAFTAR PUSTAKA}

Green, A. (2004). Caring Behaviors as Perceived by Nurse Practitioners.
Jurnal of the American Academy of Nurse Practitioners. 16 (7). 283-290.

Kumbadewi, L. (2016). Pengaruh Umur, Pengalaman Kerja, Upah, Teknologi dan Lingkungan Kerja terhadap Produktivitas Karyawan. E-journal Bisma Universitas Ganesha Jurusan Manajemen volume 4.

Mochtar, dkk. (2013). Faktor yang Berhubungan Dengan Stres Pada Perawat.

Muchlas, M. (2008). Perilaku organisasi. Yogyakarta: Gadjah Mada University Press.

Notoatmodjo, S. (2012). Metedologi Penelitian Kesehatan. Jakarta: Rineka Cipta.

Nopa, I. (2016). Pengaruh Stres Kerja Terhadap Kinerja Perawat Ruang Rawat Inap Di RSUD Tanjung Pura Langkat.

Putri, I. I. (2018). Hubungan Antara Tingkat Stres Kerja Perawat dengan Perilaku Caring Perawat.

Rachmawati, Evy. "50,9 Persen Perawat Alami Stres Kerja": http://www.kompas.com/kesehatan/5 $\underline{0,9}$ Persen Perawat Alami Stres Kerja-Kompas Cyber Media, 2007 (diakses pada tanggal 20 Desember 2009)

Renoningsih, D. P. (2016). Faktor-faktor yang Berhubungan dengan Penerapan Patient Safety pada Perawat di Instalasi Rawat Inap Rumah Sakit Umum Pancaran Kasih Manado. Ejournalhealth.com.

Rika. (2012). Perilaku Caring Perawat dalam Melakukan Asuhan Keperawatan pada Pasien di Ruang Rawat Inap RSUD Dr. Tengku Mansyur Tanjungbalai. 
Watson, J \& Robert, B. (2012). View Point: Caring Science Meets Hearts Science: A Guide to Authentic Caring Practice. http://americannurse today.com/viewpoint-caring-sciencemeets-hearts-science-a-guide-to-auth entic-caring-practice/. Publication Date: August 2012 Vol.7 No.8 (diakses 28 September 2015).

WHO. (2011). Panduan Kurikulum Keperawatan Pasien. Dalam http://apps.who.int/iris/bitstream/han dle/10665/44641/9789241501958_id .pdf;jessesionid=119DBDA8FB64D 87FFB2B8F00274985D2? sequence= 26 diakses pada 16 Oktober 2018.

Perry \& Potter. (2004). Fundamentals of Nursing: Concepts, Process, and Practice, 4th Edition. Missouri: Mosby-Year Book Inc. 